\title{
Low energy plasma treatment of a proton exchange membrane used for low temperature fuel cells
}

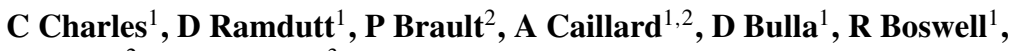 \\ H Rabat ${ }^{2}$, and A Dicks ${ }^{3}$ \\ ${ }^{1}$ Space Plasma, Power, and Propulsion group, Research School of Physical Sciences and \\ Engineering, Australian National University, Canberra, ACT 0200, Australia \\ 2 GREMI-CNRS Laboratory, University of Orléans, BP 6744, F-45067, Orléans, France \\ ${ }^{3}$ School of Engineering, The University of Queensland, Brisbane, QLD 4072, Australia
}

Received 18 May 2006, in final form 29 August 2006

Published 27 March 2007

Online at stacks.iop.org/PPCF/49/A73

\begin{abstract}
A low energy $(\sim 30 \mathrm{~V})$ plasma treatment of Nafion, a commercial proton exchange membrane used for low temperature fuel cells, is performed in a helicon radiofrequency $(13.56 \mathrm{MHz})$ plasma system. For argon densities in the $10^{9}-10^{10} \mathrm{~cm}^{-3}$ range, the water contact angle (hydrophobicity) of the membrane surface linearly decreases with an increase in the plasma energy dose, which is maintained below $5.1 \mathrm{~J} \mathrm{~cm}^{-2}$, and which results from the combination of an ion energy dose (up to $3.8 \mathrm{~J} \mathrm{~cm}^{-2}$ ) and a photon (mostly UV) energy dose (up to $1.3 \mathrm{~J} \mathrm{~cm}^{-2}$ ). The decrease in water contact angle is essentially a result of the energy brought to the surface by ion bombardment. The measured effect of the energy brought to the surface by UV light is found to be negligible.
\end{abstract}

\section{Introduction}

A major thrust of the hydrogen economy is to replace carbon-based fuels in transportation with hydrogen [1]. One of the most promising candidates for this particular application is the proton exchange membrane fuel cell (PEMFC) as it operates at low temperatures (less than $110^{\circ}$ celsius), is rather efficient, can be minatiurized and can cover a large power range. Fuel cell buses are being tried in a number of countries as a result of the extensive research and development of these fuel cells for the past few decades.

The use of plasmas for treating or manufacturing PEMFC components has acquired increasing interest over the past few years as the possibility of transferring the know-how of the microelectronics revolution of the 1970s to the hydrogen sector would open new paths for rapid commercialization. The properties of thin films deposited from a plasma are critically dependent on the flux, energy and charge state of the particles striking the growing surface. Plasmas may improve deposition quality, decrease process time or may simply be used as an aid to a chemically based process [2].

Plasma sputter deposition of the platinum catalyst onto porous films of carbon used for fuel cell electrodes has already shown great promise: aggregates of platinum are detected in the 
film with a density profile which decreases away from the surface exposed to the plasma. The small size of the nano-aggregates allows very effective catalytic action necessary for efficient fuel cell operation $[3,4]$. The energy deposited by the plasma can also be used to functionalize commercial Nafion proton exchange membranes for improving fuel cell performance [5] suggesting the necessity of controlling the various plasma parameters for alternate scenarios such as the plasma deposition of the proton exchange membrane [6].

Commercially available Nafion is an ion exchange membrane which is often used in PEMFCs. It consists of fluorocarbon chains terminated by sulfonic groups $\left(\mathrm{SO}_{3}^{-}\right)$, hence combining hydrophilic (in the bulk) and hydrophobic (at the surface) properties necessary for a good proton conductivity from the anode $\left(\mathrm{H}_{2}\right.$ side) to the cathode $\left(\mathrm{O}_{2}\right.$ side $)$ and good drainage of the water formed from catalysis at the cathode. In operation the membrane needs to be hydrated.

Recent studies have shown how plasmas can be used for the surface treatment of Nafion [5] or for the plasma assisted deposition of 'Nafion-like' polymers [6]: Cho et al have shown that bombarding the surface of Nafion with $1 \mathrm{keV}$ Ar ion doses of $10^{15}-10^{17} \mathrm{~cm}^{-2}$ changes the surface roughness and hydrophobicity of the membrane (with increased fuel cell performance) without altering the proton conductivity. Mahdjoub et al [6] have recently shown that thin films of plasma-polymerized proton conductive membranes could be deposited by plasma polymerization of trifluoromethane sulfonic acid $\left(\mathrm{CF}_{3} \mathrm{SO}_{3} \mathrm{H}\right), 1,3$-butadiene and styrene mixtures in glow or afterglow argon discharges. Their results suggest that the type of discharge has an important impact on the micro-structure of the plasma deposited film and on the resulting proton conductivity.

Previous studies on the plasma deposition of silicon dioxide from a variety of precursors initially in solid, liquid or gas phases (solid $\mathrm{Si} / \mathrm{O}_{2}$ plasma, liquid tetraethoxysilane (TEOS) $/ \mathrm{O}_{2}$ plasma, silane $\left(\mathrm{SiH}_{4}\right) / \mathrm{O}_{2}$ plasma, in a variety of radiofrequency discharges have shown that the plasmas can often be successfully diagnosed towards a better understanding and control of the structural properties of the deposited material and of their corresponding electrical, optical or mechanical properties [7-9]. Combining TEOS and Nafion has also been recently investigated [10]. The present study is limited to the analysis of the change in hydrophobicity of Nafion samples treated in a low energy plasma diffusing from a radiofrequency helicon source.

\section{Experimental set-up}

(a) Membrane preparation. Prior to the plasma treatment, the Nafion 115 is cut into $1.5 \times 4 \mathrm{~cm}$ rectangles, cleaned in $3 \% \mathrm{H}_{2} \mathrm{O}_{2}$ at $60^{\circ} \mathrm{C}$ for $60 \mathrm{~min}$, rinsed in deionized water then again cleaned in $1 \mathrm{M} \mathrm{H}_{2} \mathrm{SO}_{4}$ at $60^{\circ} \mathrm{C}$ or $60 \mathrm{~min}$ before a final rinse in deionized water. The samples are subsequently dried in an oven for $\sim 20 \mathrm{~h}$ at $100^{\circ} \mathrm{C}$ [11]. For the plasma treatment each sample is mounted on a holder and both sides are exposed to the plasma over an area of approximately $1.5 \times 2 \mathrm{~cm}$.

(b) Membrane treatment. The sample and holder are placed in a low pressure radiofrequency argon plasma expanding from a helicon source in a horizontal system called 'Chi Kung' [12] shown in figure 1. It consists of a helicon source $15 \mathrm{~cm}$ in diameter (a $32 \mathrm{~cm}$ long cylindrical glass tube terminated with a $1 \mathrm{~cm}$ thick glass plate and surrounded by a $20 \mathrm{~cm}$ long doublesaddle antenna) attached contiguously to an earthed aluminium diffusion chamber $30 \mathrm{~cm}$ long and $32 \mathrm{~cm}$ in diameter in which the holder is placed, with the sample electrically floating. The antenna is fed from a rf matching network/generator system operating at $13.56 \mathrm{MHz}$. The 


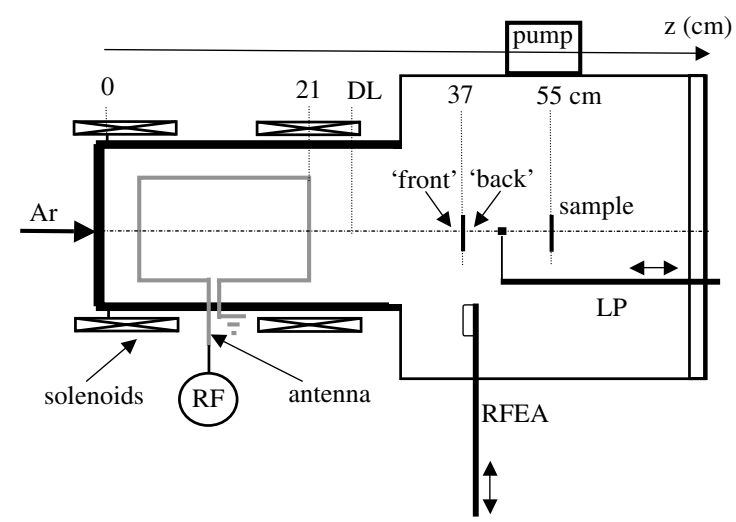

Figure 1. Schematic of 'Chi Kung', the helicon plasma reactor used for the plasma treatment of the Nafion samples, showing major components (DL: double-layer, RFEA: retarding field energy analyzer, LP: langmuir probe).

Table 1. Results on the plasma treated Nafion samples (ordered by increasing energy dose $E_{\text {ion }}$ ): operating conditions are the exposure time $t$, the radiofrequency power $P_{\mathrm{rf}}$ and the axial position $z$; the parameters at the Nafion surface are the measured ion density $n_{\text {ion }}$, the ion energy dose $E_{\text {ion }}$ calculated using equation (1) and the measured water contact angle CA.

\begin{tabular}{llccllll}
\hline Sample number & Side & $t(\mathrm{~s})$ & $P_{\text {rf }}(\mathrm{W})$ & $z(\mathrm{~cm})$ & $n_{\text {ion }}\left(\mathrm{cm}^{-3}\right)$ & $E_{\text {ion }}\left(\mathrm{J} \mathrm{cm}^{-2}\right)$ & $\mathrm{CA}\left(^{\circ}\right)$ \\
\hline 1 & Back & 6 & 250 & 55 & $6 \times 10^{9}$ & 0.23 & 115 \\
2 & Back & 6 & 250 & 37 & $6 \times 10^{9}$ & 0.23 & 116 \\
3 & Front & 6 & 250 & 55 & $10 \times 10^{10}$ & 0.38 & 121 \\
4 & Back & 60 & 80 & 37 & $3.6 \times 10^{9}$ & 1.4 & 90 \\
5 & Front & 60 & 80 & 37 & $6 \times 10^{9}$ & 2.29 & 78 \\
6 & Back & 60 & 250 & 55 & $6 \times 10^{9}$ & 2.29 & 70 \\
7 & Back & 60 & 250 & 37 & $6 \times 10^{9}$ & 2.29 & 68 \\
8 & Front & 60 & 250 & 37 & $10^{10}$ & 3.81 & 51 \\
\hline
\end{tabular}

argon feed gas is introduced at the closed end of the source to give a constant pressure of 0.3 mTorr and the turbo-molecular/rotary pumping system is connected to the sidewall of the chamber. The base pressure is $2 \times 10^{-6}$ Torr, the pressure being measured with an ion gauge and a baratron gauge, both attached to the diffusion chamber. Two solenoids situated around the source are used to create an expanding magnetic field of about $130 \mathrm{G}$ in the source centre decreasing to a few tens of Gauss in the diffusion chamber.

The plasma used for the sample treatment has been fully characterized for these operating conditions [12] by using a retarding field energy analyzer and a Langmuir probe and the main parameters investigated in this study are the exposure time $(t=6$ or $60 \mathrm{~s})$, the radiofrequency power $\left(P_{\mathrm{rf}}=80\right.$ or $\left.250 \mathrm{~W}\right)$ and the holder position $(z=37.5$ or $55 \mathrm{~cm})$ as shown in table 1 . The 'front' and 'back' sides of the sample are, respectively, referred to as the sides facing or not facing the helicon source (figure 1).

The main motivation for using this particular plasma system and operating conditions was an optimized and well-documented diagnosis and control of the spatial and temporal characteristics of the plasma parameters such as the ion energy distribution function, the plasma potential and density and the electron temperature. These conditions correspond to the spontaneous formation of a double layer (strong potential drop of about $20 \mathrm{~V}$ ) at about 
$z=25 \mathrm{~cm}$ so that the measured ion energy distribution impacting the front side at $z=37.5 \mathrm{~cm}$ consists of a population of cold ions ( $\sim 85 \%$ of the total ion density) and a population of fast ions ( $\sim 15 \%$ at twice the Bohm velocity). At $z=55 \mathrm{~cm}$, the latter is not present and has been 'replaced' by a distribution of fast neutrals (a result of charge exchange collisions) so that the front side of the sample is impacted by the cold ion population and the fast neutrals. The possible second order effect associated with the small fraction of fast ions or fast neutrals will be presently neglected. For both positions, the backside is impacted by the cold ion population only. An average ion density $n_{\text {ion }}$ is measured which is shown in table 1 . The energy of the ions impinging the sample during the plasma treatment is also kept rather constant at about the measured plasma potential of $32 \mathrm{~V}$ since the pressure and magnetic field are constant.

It is well known that UV light emitted by the plasma brings energy to the sample surface [13]. Consequently an additional experiment was carried out to get some insight into the respective effects of the ion and UV photon bombardment onto the Nafion surface during plasma treatment. A series of Nafion samples was treated under an i-line filtered $\mathrm{Hg}$ lamp $(365 \mathrm{~nm})$ which is used for exposing patterns on photoresist. This was the shortest wavelength and highest power available on site and could provide adequate energy doses. The intensity measured using a light meter at the exposed surface of Nafion was $1.5 \mathrm{~mW} \mathrm{~cm}^{-2}$ and the intensity below the Nafion was $1.09 \mathrm{~mW} \mathrm{~cm}^{-2}$. The Nafion was placed on a Si wafer coated in backing anti-reflective coating which has near zero reflection at $365 \mathrm{~nm}$. The absorbed dose could therefore be calculated as $0.41 \mathrm{~mW} \mathrm{~cm}^{-2}$ throughout the bulk material. The exposure times were $6 \mathrm{~s}, 60 \mathrm{~s}, 600 \mathrm{~s}, 1800 \mathrm{~s}$ and $6000 \mathrm{~s}$ giving energy doses of $2.46 \mathrm{~mJ} \mathrm{~cm}^{-2}$, $24.6 \mathrm{~mJ} \mathrm{~cm}^{-2}, 246 \mathrm{~mJ} \mathrm{~cm}^{-2}, 738 \mathrm{~mJ} \mathrm{~cm}^{-2}$ and $2460 \mathrm{~mJ} \mathrm{~cm}^{-2}$, respectively.

(c) Membrane characterization. To investigate the effect of low energy plasma treatment on the hydrophobicity of the Nafion membrane surface, water contact angle measurements were performed by the sessile drop method using a KSV contact angle goniometer [5, 14, 15]. The repeatability of the measurement was verified over several cycles of increase and decrease in the volume of the drop. The advancing contact angle was taken as the contact angle averaged over a time period of about $40 \mathrm{~s}$ from the time at which the contact angle reached equilibrium. The results are shown in table 1 . The value measured for the untreated Nafion is $115^{\circ}$.

\section{Results and discussion}

(a) Energy dose from ion flux. The measured plasma density $n_{\text {ion }}$ (at the edge of the sheath in front of the sample) corresponding to the various operating conditions is shown in table 1. It is kept in the $10^{9}-10^{10} \mathrm{~cm}^{-3}$ range. Combined with the given exposure time and an ion energy given by the measured plasma potential $\left(V_{\mathrm{p}} \sim 32 \mathrm{~V}\right)$, the energy dose on the Nafion surface integrated over the complete treatment is obtained using

$E_{\text {ion }}\left(\mathrm{J} \mathrm{cm}^{-2}\right)=t e \mu_{\text {ion }}\left(V_{\mathrm{p}}-V_{\mathrm{f}}\right)=t e n_{\mathrm{ion}} \sqrt{\frac{2 e\left(V_{\mathrm{p}}-V_{\mathrm{f}}\right)}{M}}\left(V_{\mathrm{p}}-V_{\mathrm{f}}\right) \approx t e n_{\mathrm{ion}} \sqrt{\frac{2 e V_{\mathrm{p}}}{M}} V_{\mathrm{p}}$,

where $e$ is the electron charge, $M$ is the argon ion mass, and $\mu_{\text {ion }}$ is the argon ion flux bombarding the Nafion surface. The measured floating potential $V_{\mathrm{f}}$ is close to zero and the acceleration of the ions in the presheath is neglected (the measured electron temperature is about $8 \mathrm{eV}$ ). The water contact angle measurements are shown in table 1 and plotted as a function of $E_{\text {ion }}$ on figure 2. The contact angle decreases from $120^{\circ}$ to $51^{\circ}$ when the energy dose is increased from 0.2 to $4 \mathrm{~J} \mathrm{~cm}^{-2}$, thus reducing the hydrophobicity. 


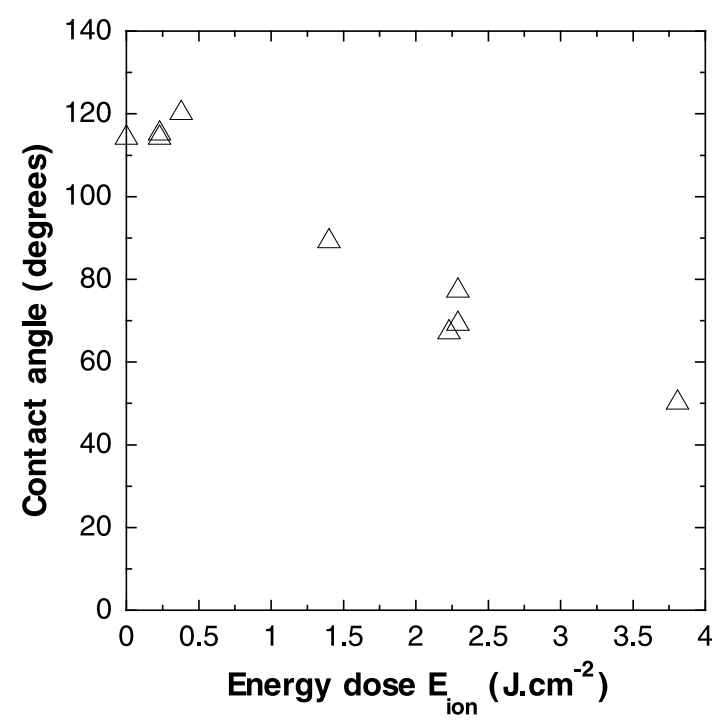

Figure 2. Measured water contact angle as a function of the ion energy dose $E_{\text {ion }}$ calculated using equation 1 . The measured plasma parameters and operating conditions are specified in table 1.

In the diffusion chamber there is rather good uniformity in plasma potential and plasma density along the $z$-axis mostly as a result of the low operating pressure $(0.3 \mathrm{mTorr})$. The measured $n_{\text {ion }}(55 \mathrm{~cm}) / n_{\text {ion }}(37 \mathrm{~cm})$ density ratio reported in the literature is about 0.75 at $0.3 \mathrm{mTorr}$ and 0.2 at $3 \mathrm{mTorr}$ [16]. A theory for the formation of this low pressure, current-free double layer configuration has been recently developed which agrees quite well with the main experimental results and which gives a slightly lower $n_{\text {ion }}(55 \mathrm{~cm}) / n_{\text {ion }}(37 \mathrm{~cm})$ density ratio of 0.6 at $0.3 \mathrm{mTorr}[17,18]$. In the present study, the density was measured with the presence of the sample and sample holder: the $n_{\text {ion }}(55 \mathrm{~cm}) / n_{\text {ion }}(37 \mathrm{~cm})$ density ratio measured for both operating powers and on both sides of the samples was 1 . Hence, the same density is obtained for samples 1 and $2\left(n_{\text {ion }}=6 \times 10^{9} \mathrm{~cm}^{-3}\right)$ or for samples 6 and $7\left(n_{\text {ion }}=6 \times 10^{9} \mathrm{~cm}^{-3}\right)$ in table 1 . The measured back/front density ratio was 0.6 for both positions on the $z$-axis as illustrated by samples $3\left(n_{\text {ion }}=10^{10} \mathrm{~cm}^{-3}\right)$ and $2\left(n_{\text {ion }}=6 \times 10^{9} \mathrm{~cm}^{-3}\right)$ or samples 8 and 7 in table 1 . The low/high power density ratio was 0.6 as shown by samples 5 (high power, $n_{\text {ion }}=10^{10} \mathrm{~cm}^{-3}$ ) and 8 (low power, $n_{\text {ion }}=6 \times 10^{9} \mathrm{~cm}^{-3}$ ). Previous measurements of the radial density profiles at $z=37 \mathrm{~cm}$ and $z=55 \mathrm{~cm} \mathrm{[12]} \mathrm{show} \mathrm{that} \mathrm{the} \mathrm{variation} \mathrm{across}$ the sample can be neglected (less than 5\%). Still, the density calibration and contact angle measurements were performed at the centre of the sample. The diameter of the water drop at the sample surface was about $3 \mathrm{~mm}$.

(b) Energy dose from UV light. The ionization and excitation rates are quite similar for argon and we assume that the photon flux is equal to the ion flux. Since the excitation energy threshold $E_{\mathrm{ex}}$ and the plasma potential $V_{\mathrm{p}}$ are 11 and $32 \mathrm{~V}$, respectively, the energy dose associated with the light emission of the plasma (mostly UV) is about three times less $\left(E_{\mathrm{ex}} / V_{\mathrm{p}}\right)$ than that related to the ion bombardment [13]. The actual ratio may even be smaller and this estimation is simply used as a guide to find the range of energy doses to be investigated in the UV light exposure experiment. The maximum value of $E_{\mathrm{UV}}\left(\sim 1 / 3 E_{\mathrm{ion}}\right)$ for the present series of experiments is $1.27 \mathrm{~J} \mathrm{~cm}^{-2}$. 


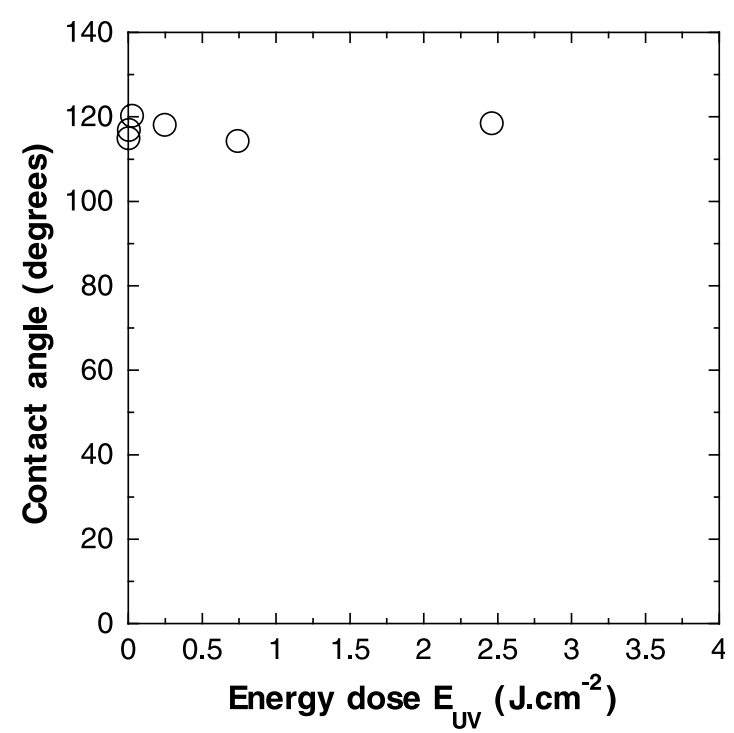

Figure 3. Measured water contact angle as a function of the 'UV light' energy dose $E_{\mathrm{UV}}$ from an $\mathrm{Hg}$ line at $365 \mathrm{~nm}$.

The results from water contact angle measurement versus $E_{\mathrm{UV}}$ of a series of Nafion samples treated under an i-line filtered $\mathrm{Hg}$ lamp $(365 \mathrm{~nm})$ are shown in figure 3. No major change of hydrophobicity is seen up to an energy dose of $2.5 \mathrm{~J} \mathrm{~cm}^{-2}$, which is greater than the maximum value of $E_{\mathrm{UV}} \sim 1.27 \mathrm{~J} \mathrm{~cm}^{-2}$ which corresponds to the plasma treatment. Hence it is reasonable to assume that the change in hydrophobicity is a result of the energy brought to the surface by ion bombardment only. We note that the actual energy dose brought to the sample surface during the plasma treatment $\left(0-5.1 \mathrm{~J} \mathrm{~cm}^{-2}\right)$ corresponds to the sum of the energy dose from ion bombardment $\left(0-3.8 \mathrm{~J} \mathrm{~cm}^{-2}\right)$ and the energy dose from the light emission (mostly UV) of the plasma $\left(0-1.3 \mathrm{~J} \mathrm{~cm}^{-2}\right)$, although the latter has no major effect on the hydrophobicity.

The present results are strikingly different from the results of Cho et al [5] and it is very likely that the present decrease in hydrophobicity would be detrimental to the fuel cell performance. Cho et al used an ion implantation system with $1.2 \mathrm{keV}$ ions where the ion dose was in the $10^{15}-10^{17} \mathrm{~cm}^{-2}$ range. Their exposure time is not quoted. Substantial improvement in the fuel cell response was obtained when comparing treated and non-treated membraneelectrode assemblies with an increased fuel cell power density by a factor of 2 obtained for the ion dose of $10^{16} \mathrm{~cm}^{-2}$. This was attributed to an enhanced surface roughness. This is in stark contradiction to the present results although we use a much lower energy treatment $(\sim 30 \mathrm{~V})$.

Mahdjoub et al [6], however, have reported a decrease in proton conductivity when using a glow discharge rather than an after-glow discharge to deposit their plasma-polymerized membranes at operating powers of a few tens of watts and a few hundreds of mTorr. This suggests that a good control and understanding of the plasma is of importance when developing new processes such as plasma treatment of Nafion, plasma assisted deposition of Nafion-like polymers and plasma deposition of electrodes onto the Nafion itself [19].

Various mechanisms linking a decrease in hydrophobicity (smaller contact angle values) with changes in the surface chemistry of polymers have been discussed in the literature. Khayet [20] has shown that a chemical treatment yielding a depletion of fluorine on a 
polymeric membrane surface leads to a decrease in contact angle, i.e. to a decrease in hydrophobicity. A plasma treatment of polymer membranes using $\mathrm{CF}_{4} / \mathrm{Ar}$ mixtures also confirms that fluorination leads to hydrophobic membranes [21]. Other studies on Nafion itself [22] have shown that a treatment which leads to the migration of the hydrophilic $\mathrm{SO}_{3}^{-}$ sulfonic groups to the surface, would induce a decrease in contact angle. Finally, Kim et al [15] have shown that the hydrophobic properties of polymer surfaces modified using plasma source ion implantation are directly related to the amount of fluorine-containing functional groups (mostly $\mathrm{CF}_{2}$ and $\mathrm{CF}_{3}$ groups) at the surface and to the $\mathrm{F} / \mathrm{C}$ atomic composition ratio at the surface. Consequently, the decrease in contact angle presently measured for increasing ion energy doses may be associated with a decrease in the $\mathrm{F} / \mathrm{C}$ atomic composition ratio at the surface and/or to an increase in the hydrophilic $\mathrm{SO}_{3}^{-}$sulfonic group content at the surface. The latter could result from a migration of these groups from the bulk to the surface or from a preferential etch of CF polymer chains.

\section{Conclusion}

The present study has dealt with preliminary results on water contact angle measurements of plasma treated Nafion, in a situation where the plasma has been characterized using electrostatic probes. The treated surface exhibits a decrease in hydrophobicity with an increased energy dose. The energy dose provided by the ion bombardment during the plasma treatment is responsible for this change while the energy dose from UV light has little effect on the present energy range of a few joules per square centimeter. Further experiments will focus on fuel cell performances.

\section{References}

[1] Carrette L, Friedrich K A and Stimming U 2001 Fuel Cells 15

[2] Brault P, Roualdes S, Caillard A, Thomann A L, Mathias J, Durand J, Coutanceau C, Leger J M, Charles C and Boswell R 2006 Eur. Phys. J. Appl. Phys. 34 151-6

[3] Brault P, Caillard A, Thomann A L, Mathias J, Charles C, Boswell R, Escribano S, Durand J, Roualdes S and Sauvage T 2004 J. Phys. D: Appl. Phys. 37 3419-23

[4] Caillard A, Brault P, Mathias J, Charles C and Boswell R W 2005 Surf. Coat. Technol. 200 391-4

[5] Cho S A, Cho E A, Oh I H, Kim H J, Ha H Y, Hong S A and Ju J B 2006 J. Power Sources 155 286-90

[6] Mahdjoub H, Roualdes S, Sistat P, Pradeilles N, Durand J and Pourcelly G 2005 Fuel Cells 5277

[7] Charles C, Garcia P, Grolleau B and Turban G 1992 J. Vac. Sci. Technol. A 10 1407-13

[8] Charles C, Giroult-Matlakowski G, Boswell R W, Goullet A, Turban G and Cardinaud C 1993 J. Vac. Sci. Technol. A 11 2954-63

[9] Au V, Charles C and Boswell R W 2006 J. Phys. D: Appl. Phys. 39 164-71

[10] Ladewig B P, Webb R E, Martin D J, Diniz da Costa J C, and Lu G Q 2005 Brazilian J. Mater. Sci. Eng. 7 51-9

[11] Weng D, Wainright J S, Landau U and Savinell R F 1996 J. Electrochem. Soc. 143 1260-63

[12] Charles C and Boswell R W 2004 Phys. Plasmas 11 1706-14

[13] Lieberman M A and Lichtenberg A J 2005 Principles of Plasma Discharges and Materials Processing 2nd edn (New York: Wiley) chapter 3

[14] Wang J H, Claesson P M, Parker J L and Yasuda H 1994 Langmuir 103887

[15] Kim Y, Lee Y, Han S and Kim K J 2005 Surf. Coat. Technol. $2004763-9$

[16] Charles C and Boswell R W 2003 Appl. Phys. Lett. 82 1356-8

[17] Lieberman M A and Charles C 2006 Phys. Rev. Lett. 97 1-4

[18] Lieberman M A, Charles C and Boswell R W 2006 J. Phys. D: Appl. Phys. 39 3294-304

[19] Rabat H, Caillard A, Brault P, Charles C and Boswell R W 2006 private communication

[20] Khayet M Appl. Surf. Sci. 2006238 269-72

[21] Finot E, Roualdes S, Kirchner M, Rouessac V, Berjoan R, Durand J, Goudonnet J P and Cot L 2006 Appl. Surf. Sci. 287 326-38

[22] Sangribsub S, Tangboriboonrat P, Pith T and Decher G 2006 Polym. Bull. 53 425-34 